\title{
Pyropia yezoensis glycoprotein regulates antioxidant status and prevents hepatotoxicity in a rat model of D-galactosamine/lipopolysaccharide-induced acute liver failure
}

\author{
JEONG-WOOK CHOI, IN-HYE KIM, YOUNG-MIN KIM, MIN-KYEONG LEE and TAEK-JEONG NAM \\ Department of Food and Life Science, Pukyong National University, Busan 608-737, Republic of Korea
}

Received January 24, 2015; Accepted November 18, 2015

DOI: $10.3892 / \mathrm{mmr} .2016 .4932$

\begin{abstract}
The present study aimed to investigate the effects of Pyropia yezoensis glycoprotein (PYGP) on hepatic antioxidative enzyme activity and mitogen-activated protein kinase (MAPK) phosphorylation in a rat model of D-galactosamine/lipopolysaccharide (D-GalN/LPS)-induced hepatotoxicity. Glutamic-oxaloacetic transaminase (GOT) and glutamic-pyruvic transaminase (GPT) were measured to determine the severity of hepatotoxicity. Treatment with D-GalN/LPS significantly increased the GOT, GPT and lipid peroxidation levels, and decreased the antioxidant capacity of the rats. Treatment with PYGP (150 and $300 \mathrm{mg} / \mathrm{kg} /$ body weight) decreased the levels of GOT, GPT and lipid peroxidation levels. The activities of antioxidative enzymes, including catalase, glutathione S-transferase and glutathione were upregulated following PYGP treatment. Furthermore, D-GalN/LPS-induced MAPK phosphorylation, and inducible nitric oxide synthase (iNOS) and cyclooxygenase-2 (COX-2) protein expression were downregulated by PYGP. These results indicated that PYGP may exert hepatoprotective effects via the upregulation of antioxidative enzymes, and the downregulation of the MAPK signaling pathway and iNOS and COX-2 expression.
\end{abstract}

\section{Introduction}

Acute liver failure (ALF), which is characterized by coagulopathy and encephalopathy, is associated with a high mortality rate $(1,2)$. ALF may be induced by alcohol, viral hepatitis, bacteria or hepatotoxic drugs (3), and there is currently no available therapy for ALF other than liver transplantation (4).

D-galactosamine (D-GalN) and lipopolysaccharide (LPS) are often used to generate hepatitis test models (5). Animal models are used in hepatoprotective drug screening, and to

Correspondence to: Professor Taek-Jeong Nam, Department of Food and Life Science, Pukyong National University 599-1 Daeyeon 3-dong, Nam-gu, Busan 608-737, Republic of Korea

E-mail:namtj@pknu.ac.kr

Key words: D-GalN/LPS, MAPK, glycoprotein, Pyropia yezoensis glycoprotein elucidate the mechanisms underlying clinical liver dysfunction (6). D-GalN induces a loss of uridine triphosphate via the galactose pathway, and inhibits RNA and protein synthesis (7), thus resulting in hepatic necrosis and apoptosis due to metabolic changes (8). LPS activates liver macrophages, which secrete diverse proinflammatory cytokines, thus inducing hepatic necrosis and reducing the production of antioxidant enzymes (9).

The D-GalN/LPS hepatotoxic model induces inflammatory reactions and oxidative stress within the liver $(10,11)$, due to increased inflammation and expression of inducible nitric oxide synthase (iNOS) and cyclooxygenase-2 (COX-2) (12). iNOS has an important role in drug-induced liver injury (13), and COX-2 has an essential role in D-GalN/LPS-induced inflammation (14). Inflammation leads to the production of reactive oxygen species (ROS), including $\mathrm{H}_{2} \mathrm{O}_{2}, \mathrm{O}_{2}{ }^{-}$and $\mathrm{OH}^{-}(15)$. ROS attack polyunsaturated fatty acids in the cell membrane via lipid peroxidation, and trigger various pathological states, including oxidative stress (16).

Mitogen-activated protein kinases (MAPKs) comprise three major proteins: C-jun $\mathrm{NH}_{2}$-terminal kinase (JNK), p38 MAPK and extracellular signal-regulated kinase (ERK). Phosphorylated MAPK proteins have various roles in oxidative stress and inflammatory diseases (17). In particular, activated JNK has an important role in hepatic injury via activation of the caspase cascade and induction of liver cell necrosis (18).

Pyropia yezoensis is a type of red algae, which has long been considered an important food source in Korea, Japan and China (19). Various previous studies have demonstrated the therapeutic effects of $P$. yezoensis, including chemoprotective (20), anticancer (21) and anti-inflammatory activities (22). There are currently no studies regarding the antioxidative activities of $P$. yezoensis glycoprotein (PYGP) against D-GalN/LPS-induced hepatotoxicity. The present study aimed to investigate the anti-inflammatory effects of PYGP against D-GalN/LPS in vivo.

\section{Materials and methods}

Preparation of PYGP. P. yezoensis was purchased in 2014 (Suhyup, Seoul, South Korea). P. yezoensis powder (40 g) was diluted with $1 \mathrm{~L}$ distilled water and stirred for $4 \mathrm{~h}$ at room temperature. The solution was then centrifuged at $3,000 \mathrm{x} \mathrm{g}$ and $4^{\circ} \mathrm{C}$ for $20 \mathrm{~min}$, and vacuum filtered. Triple the volume of 
ethanol was added to the solution (total quantity of filtrate $\mathrm{x} 3$ ). After $24 \mathrm{~h}$, the solution was filtered and concentrated using rotary evaporation at $40^{\circ} \mathrm{C}$. The concentrated solution was divided into $1.5 \mathrm{ml}$ tubes, freeze-dried, and stored at $-70^{\circ} \mathrm{C}$ until further use.

Experimental animals. Male Sprague-Dawley rats (6 weeks old) were purchased from Samtaco (Osan, South Korea). Animal studies were conducted in accordance with the Animal Ethics Committee of the Pukyong National University (Busan, South Korea). The rats were maintained in the following laboratory conditions: $23 \pm 3^{\circ} \mathrm{C}, 12 \mathrm{~h}$ light $/ 12 \mathrm{~h}$ dark cycle and $50 \%$ humidity, with ad libitum access to food and water.

Experimental design. The rats were randomly divided into four groups ( $\mathrm{n}=5 /$ group): Group 1, control rats received distilled water only; group 2, rats received $500 \mathrm{mg} / \mathrm{kg} /$ body weight (BW) D-GalN + $10 \mu \mathrm{g} / \mathrm{kg} / \mathrm{BW}$ LPS; group 3 , rats received $500 \mathrm{mg} / \mathrm{kg} / \mathrm{BW} \mathrm{D}-\mathrm{GalN}+10 \mu \mathrm{g} / \mathrm{kg} / \mathrm{BW}$ $\mathrm{LPS}+150 \mathrm{mg} / \mathrm{kg} / \mathrm{BW}$ PYGP; and group 4 , rats received $500 \mathrm{mg} / \mathrm{kg} / \mathrm{BW}$ D-GalN + $10 \mu \mathrm{g} / \mathrm{kg} / \mathrm{BW} \mathrm{LPS}+300 \mathrm{mg} / \mathrm{kg} / \mathrm{BW}$ PYGP. PYGP was administered orally once a day for 7 days. Hepatotoxicity was induced in the rats by intraperitoneal injection of D-GalN/LPS (Sigma-Aldrich, St. Louis, MO, USA) at a dose of $500 \mathrm{mg} / \mathrm{kg} / \mathrm{BW}$ D-GalN and $10 \mu \mathrm{g} / \mathrm{kg} / \mathrm{BW}$ LPS. The rats were sacrificed under mild ether anesthesia (Duksan Pure Chemicals Co., Ltd., Ansan, South Korea) by decapitation for blood and liver sample collection $6 \mathrm{~h}$ after induction of hepatotoxicity.

GOT/GPT measurement. The blood samples were centrifuged at $3,000 \mathrm{x}$ g for $20 \mathrm{~min}$ at $4^{\circ}$ to collect serum and stored at $-20^{\circ} \mathrm{C}$ until analysis. The activities of glutamic-oxaloacetic transaminase (GOT) and glutamic-pyruvic transaminase (GPT) in the serum samples were determined using an enzymatic analysis kit (Asan Pharmaceuticals, Hwasung, South Korea), according to the manufacturer's protocols. The absorbance was measured at $505 \mathrm{~nm}$ using a microplate reader (Benchmark Plus 10730; Bio-Rad Laboratories, Inc., Hercules, CA, USA).

Lipid peroxidation measurements. The liver tissues were added to $1 \mathrm{X}$ butyl hydroxyl toluene (Cell Biolabs, Inc., San Diego, CA, USA) and homogenized on ice at $10,000 \times \mathrm{g}$ for $5 \mathrm{~min}$ to collect the supernatant. According to the Thiobarbituric Acid Reactive Substances (TBARS) Assay kit protocol (Cell Biolabs), $100 \mu \mathrm{l}$ of sample or malondialdehyde (MDA) standard was added to microcentrifuge tubes and then $100 \mu 1$ SDS lysis solution was added, mixed thoroughly, incubated for $5 \mathrm{~min}$ at room temperature, and $250 \mu \mathrm{l}$ of TBA reagent added. Each tube was closed, incubated at $95^{\circ} \mathrm{C}$ for $60 \mathrm{~min}$, removed and then cooled to room temperature in an ice bath for $5 \mathrm{~min}$. All the sample tubes were centrifuged at $842 \times \mathrm{g}$ for $15 \mathrm{~min}$, the supernatant removed, $200 \mu 1$ was transferred, along with $200 \mu \mathrm{l}$ of MDA standard, to a 96-well microplate compatible with a microplate reader (Benchmark Plus 10730) and the absorbance read at $532 \mathrm{~nm}$.

Antioxidant enzyme measurements. Antioxidant enzyme activities, including catalase (CAT), glutathione (GSH) and glutathione S-transferase (GST), were measured in the liver samples using appropriate kits, according to the manufacturer's protocols (Catalase Assay kit, Glutathione Assay kit and Glutathione S-Transferase Assay kit; all Cayman Chemical Company, Ann Arbor, MI, USA). The absorbance was measured using a microplate reader (Benchmark Plus 10730).

Western blot analysis. Liver tissue samples were homogenized in lysis buffer [150 mM sodium chloride, $50 \mathrm{mM}$ Tris- $\mathrm{HCl}(\mathrm{pH} 7.5), 0.5 \%$ sodium deoxycholate, $0.1 \%$ sodium dodecyl sulfate (SDS), $1 \%$ Triton X-100 and $2 \mathrm{mM}$ ethylenediaminetetra-acetic acid; Intron Biotechnology, Inc., Seongnam, South Korea] containing inhibitors ( $1 \mathrm{mM} \mathrm{Na}_{3} \mathrm{VO}_{4}$, $1 \mu \mathrm{g} / \mathrm{ml}$ aprotinin, $1 \mu \mathrm{g} / \mathrm{ml}$ leupeptin, $1 \mu \mathrm{g} / \mathrm{ml}$ pepstatin A and $1 \mathrm{mM}$ phenylmethylsulfonyl fluoride; Sigma-Aldrich). Protein concentration was determined using the Bichinchoninic Acid Assay kit (Pierce Biotechnology, Inc., Rockford, IL, USA). Equal protein quantities $(20 \mu \mathrm{g})$ from each sample were separated by $10-15 \%$ SDS-polyacrylamide gel electrophoresis and transferred to a polyvinylidene fluoride membrane (EMD Millipore, Billerica, MA, USA). The membrane was blocked with $1 \%$ bovine serum albumin (BSA) in TBST [10 mM Tris- $\mathrm{HCl}$ (pH 7.5), $150 \mathrm{mM} \mathrm{NaCl}$ and $0.1 \%$ Tween 20; USB Corporation, Cleveland, OH, USA]. Subsequently, the membrane was incubated for $4 \mathrm{~h}$ at room temperature with the following primary immunoglobulin $\mathrm{G}$ antibodies, diluted to 1:1,000 in BSA/TBST: Rabbit anti-rat ERK polyclonal antibody (cat. no. sc-94), rabbit anti-rat phosphorylated (p)-ERK polyclonal antibody (cat. no. sc-7383), mouse anti-rat JNK monoclonal antibody (cat. no. sc-7345), mouse anti-rat p-JNK monoclonal antibody (cat. no. sc-6254), rabbit anti-rat p38 polyclonal antibody (cat. no. sc-7149), mouse anti-rat p-p38 monoclonal antibody (cat. no. sc-7973), mouse anti-rat iNOS polyclonal antibody (cat. no. sc-650), goat anti-rat COX-2 polyclonal antibody (cat. no. sc-1745) and rabbit antirat GAPDH polyclonal antibody which served as a loading control (cat. no. sc-25778; all Santa Cruz Biotechnology Inc., Dallas, TX, USA). The membrane was then incubated with peroxidase-conjugated anti-goat (cat. no. 81-1620), anti-mouse (cat. no. 62-6520) and anti-rabbit (cat. no. 65-6120) secondary antibodies (1:10,000; Bethyl Laboratories, Inc., Montgomery, TX, USA) for $1 \mathrm{~h}$ at room temperature. Antibody binding was visualized using the Super Signal West Pico Stable Peroxide solution and the Super Signal West Pico Luminol/Enhancer solution (Thermo Fisher Scientific, Inc., Rockford, IL, USA). The signal was developed on Kodak X-ray film (Kodak, Rochester, NY, USA) using a developer and fixer twin pack (Kodak).

Statistical analysis. The results of the present study are presented as the mean \pm standard deviation. Data were analyzed using SPSS version 10.0 software (SPSS, Inc., Chicago, IL, USA). Results were validated using analysis of variance and Duncan's multiple range test. $\mathrm{P}<0.05$ was considered to indicate a statistically significant difference.

\section{Results}

PYGP suppresses GOT and GPT levels in the serum of $D$-GalN/LPS-treated rats. GOT and GPT serum levels are 

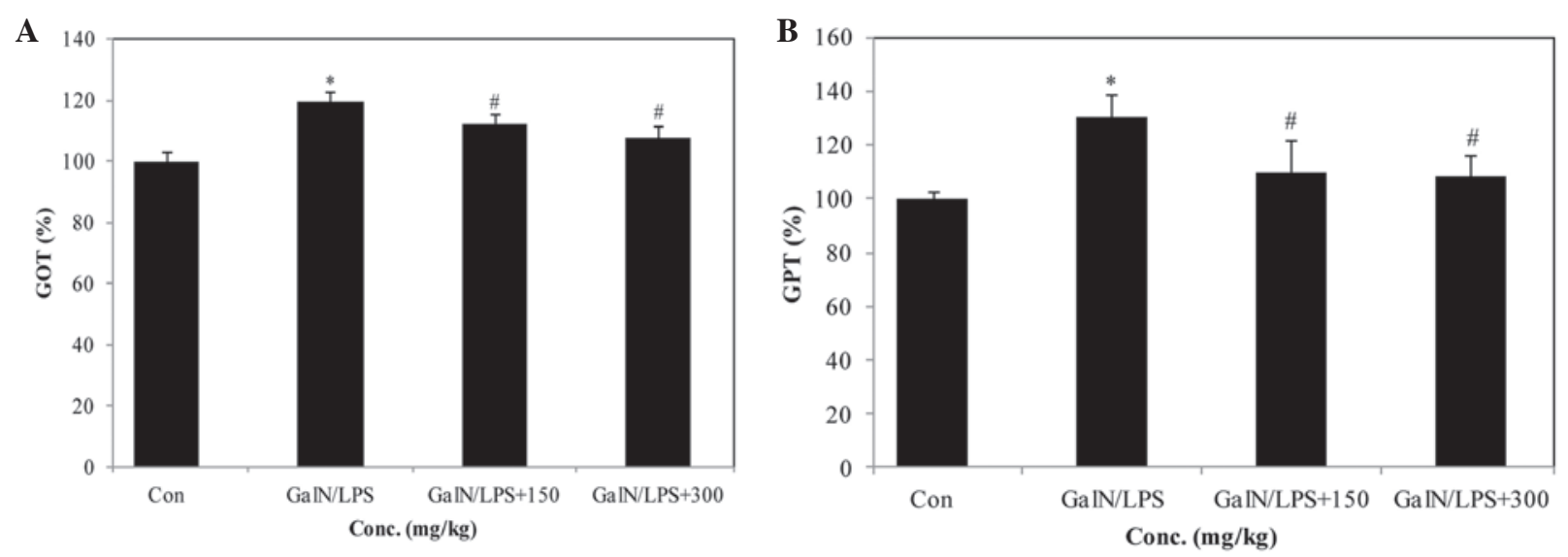

Figure 1. (A) GOT and (B) GPT levels in the serum of control and experimental rat groups. Data are presented as the mean \pm standard deviation. ${ }^{*}<0.05$ vs. the control group, ${ }^{\prime} \mathrm{P}<0.05$ vs. the GaIN/LPS group. GalN, D-galactosamine; LPS, lipopolysaccharide; $150,150 \mathrm{mg} / \mathrm{kg} / \mathrm{body}$ weight PYGP; $300,300 \mathrm{mg} / \mathrm{kg} / \mathrm{body}$ weight PYGP; PYGP, Pyropia yezoensis glycoprotein; GOT, glutamic-oxaloacetic transaminase; GPT, glutamic-pyruvic transaminase; Con, control.
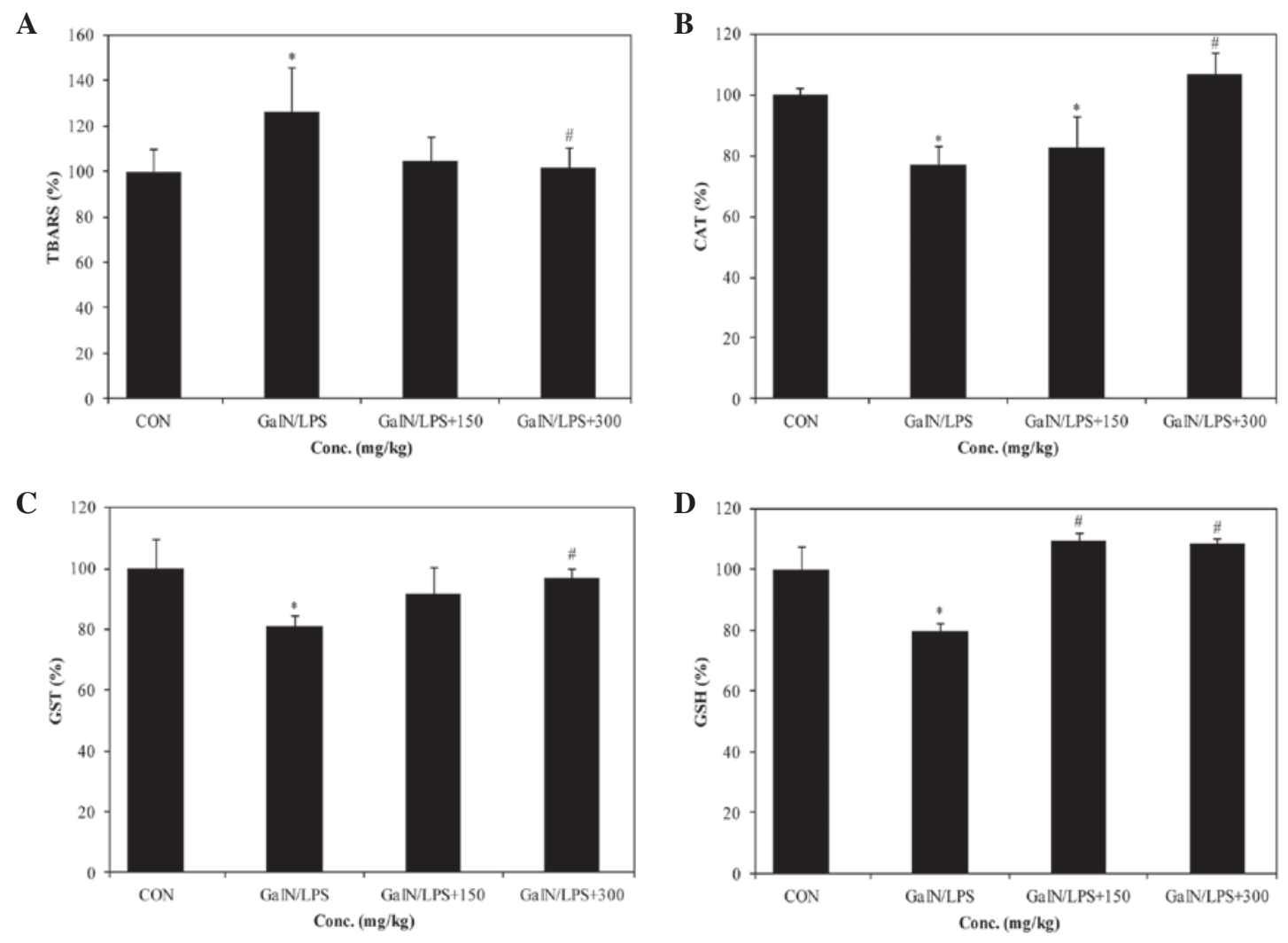

Figure 2. Levels of TBARS and antioxidant enzyme activity (CAT, GST and GSH) in the livers of control and experimental rat groups. (A) TBARS, (B) CAT, (C) GST and (D) GSH. Data are presented as the mean \pm standard deviation. ${ }^{*} \mathrm{P}<0.05$ vs. the control group, ${ }^{\#} \mathrm{P}<0.05$ vs. the GaIN/LPS group. GalN, D-galactosamine; LPS, lipopolysaccharide; $150,150 \mathrm{mg} / \mathrm{kg} /$ body weight PYGP; 300, $300 \mathrm{mg} / \mathrm{kg} /$ body weight PYGP; PYGP, Pyropia yezoensis glycoprotein; TBARS, thiobarbituric acid reactive substances; CAT, catalase; GST, glutathione S-transferase; GSH, glutathione; Con, control.

important indicators of liver function (23). Injection with D-GalN/LPS elevated the levels of GOT and GPT; however, treatment with $300 \mathrm{mg} / \mathrm{kg} / \mathrm{BW}$ PYGP significantly reduced these levels (Fig. 1A and B).

Effects of PYGP on D-GalN/LPS-induced oxidative stress and antioxidant enzyme activity. A total of $6 \mathrm{~h}$ post-D-GalN/LPS injection, the TBARS levels were determined, which indicate liver tissue lipid peroxidation. As shown in Fig. 2A, TBARS increased significantly following treatment with D-GalN/LPS. Conversely, TBARS levels in the D-GalN/LPS+PYGP 150 and D-GalN/LPS+PYGP 300 groups were markedly decreased. Furthermore, antioxidant enzyme activities were markedly decreased in the D-GalN/LPS group, as compared with in the control group. CAT levels were decreased by $\sim 20 \%$, as compared with the control group. In addition, GST and GSH levels were decreased following D-GalN/LPS treatment, however, levels were restored to control group levels following treatment with PYGP (Fig. 2B-D). 


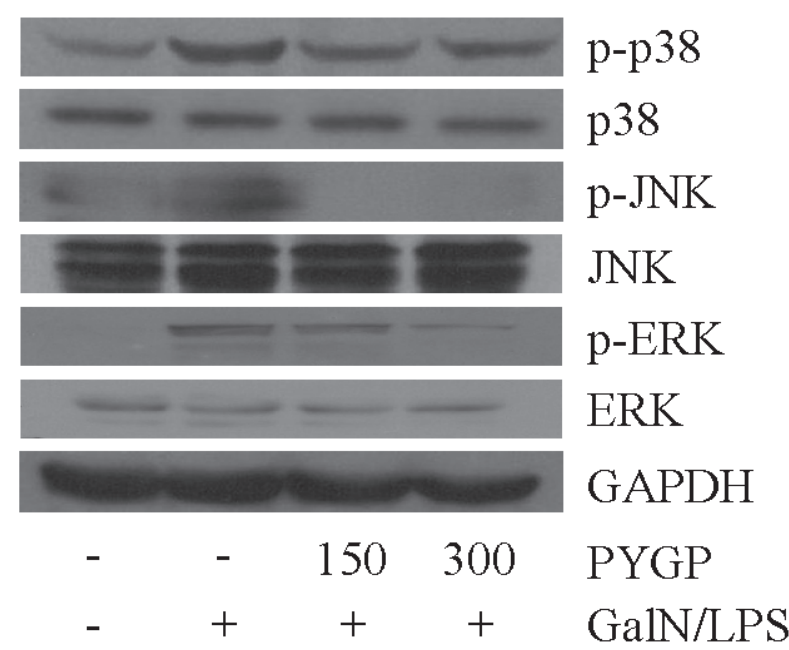

Figure 3. Expression levels of MAPK protein in the livers of control and experimental rat groups. Liver samples were homogenized in lysis buffer and western blotting was performed to determine the total protein expression and phosphorylation levels of ERK, JNK and p38 MAPK. PYGP, Pyropia yezoensis glycoprotein; GalN, D-galactosamine; LPS, lipopolysaccharide; MAPK, mitogen-activated protein kinase; ERK, extracellular signal-regulated kinase; JNK, c-jun N-terminal kinase; p-, phosphorylated; GAPDH, glyceraldehyde 3-phosphate dehydrogenase.

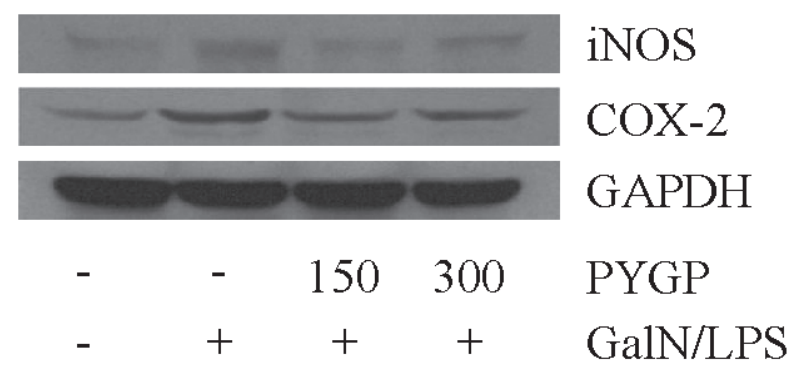

Figure 4. Expression levels of iNOS and COX-2 protein in the livers of control and experimental rat groups. Liver samples were homogenized in lysis buffer and western blotting was performed to determine the total protein expression levels of iNOS and COX-2. PYGP, Pyropia yezoensis glycoprotein; GalN, D-galactosamine; LPS, lipopolysaccharide; iNOS, inducible nitric oxide synthase; COX-2, cyclooxygenase-2 GAPDH, glyceraldehyde 3-phosphate dehydrogenase.

PYGP suppresses D-GalN/LPS-induced MAPK phosphorylation. To investigate whether PYGP was able to modulate MAPK signaling, MAPK protein expression and phosphorylation levels were detected by western blot analysis. The protein expression levels of ERK, JNK and p38 did not differ between the groups. However, the phosphorylation of these proteins increased in the D-GalN/LPS-treated group, as compared with in the control group. In the D-GalN/LPS + PYGP co-treated groups, the phosphorylation levels of these proteins were downregulated (Fig. 3). These results suggest that PYGP may inhibit D-GalN/LPS-induced MAPK phosphorylation.

Effects of PYGP on iNOS and COX-2 protein expression. To confirm the effects of PYGP on inflammation in the rat liver, D-GalN/LPS-induced iNOS and COX-2 protein expression levels were detected. Following treatment with D-GalN/LPS, the protein expression levels were markedly increased; however, treatment with PYGP prior to injection with D-GalN/LPS inhibited D-GalN/LPS-induced iNOS and COX-2 protein expression (Fig. 4). These results indicate that PYGP has an important role in the suppression of D-GalN/LPS-induced iNOS and COX-2 protein expression.

\section{Discussion}

Treating rats with a combination of D-GalN and LPS is widely used in studies researching the mechanisms underlying human ALF (24). D-GalN and LPS co-treatment induces greater critical hepatic damage, accompanied by apoptotic and necrotic changes in the liver, which closely resembles human viral hepatitis $(25,26)$. In the present study, administration of D-GalN/LPS increased GOT and GPT serum levels; however, oral administration of PYGP attenuated these levels. These results suggested that D-GalN/LPS was able to induce severe damage to hepatic membranous tissues, and PYGP may prevent this hepatotoxicity.

D-GalN/LPS hepatotoxicity induces ROS production and reduces antioxidant enzyme activity in the liver (27). Furthermore, ROS may cause cell membrane lipid peroxidation (28). Oxidative stress is a well-known factor in D-GalN/LPS-induced liver injury. Increased TBARS and conjugated dienes have previously been detected following treatment with D-GalN/LPS (29). In the present study, the levels of TBARS increased in response to D-GalN/LPS treatment; however, co-treatment with D-GalN/LPS and PYGP suppressed hepatic TBARS levels. Antioxidant enzymes, including CAT, GST and GSH are important in D-GalN/LPS hepatotoxicity. CAT catalyzes the dismutation reaction of $\mathrm{H}_{2} \mathrm{O}_{2}$, resulting in the formation of $\mathrm{H}_{2} \mathrm{O}$ and $\mathrm{O}_{2}(26) . \mathrm{GSH}$ is a substrate of GST, and GST catalyzes the conjugation of GSH with drugs and chemicals (30). In the present study, treatment with D-GalN/LPS significantly reduced the activities of CAT, GST and GSH, as compared with in the control group. Conversely, increased CAT and GST activities, and GSH levels were detected following PYGP treatment. These results suggested that PYGP exerts antioxidative effects against D-GalN/LPS-induced liver injury.

MAPKs comprise ERK, JNK and p38 proteins, which are phosphorylated by D-GalN/LPS (6). These proteins are involved in cell proliferation, differentiation, metabolism, survival and apoptosis (31). In particular, these proteins regulate cytokine production, and the expression of tumor necrosis factor- $\alpha$ and transcription factors $(32,33)$. In the present study, treatment with PYGP significantly suppressed the GalN/LPS-induced phosphorylation of ERK, JNK and p38. These results indicated that GalN/LPS and PYGP co-treatment may reduce MAPK phosphorylation.

Inflammation occurs via various biological pathways. Nitric oxide (NO) production occurs via the iNOS pathway (34); in the cell, increased iNOS protein expression produces large amounts of NO, which increases the prevalence of inflammation (35). In addition, overexpression of $\mathrm{NO}$ induces hepatic dysfunction and hepatotoxicity (36). COX-2 is associated with the pathophysiology of inflammatory dysfunction, and the production of prostaglandins and thromboxanes (37), which may lead to hepatic injury (12). In the present study, PYGP pretreatment inhibited GalN/LPS-induced iNOS and COX-2 overexpression. 
In conclusion, the present study demonstrated that PYGP may exert protective effects against D-GalN/LPS-induced ALF via inhibition of MAPK phosphorylation and iNOS and COX-2 expression. In addition, PYGP increased the activity of antioxidant enzymes.

\section{Acknowledgements}

The present study was supported by the Fishery Commercialization Technology Development Program through the Korean Institute of Planning and Evaluation of Technology in Food, Agriculture, Forestry and Fisheries (iPET) funded by the Ministry of Oceans and Fisheries (grant no. 2012300734).

\section{References}

1. Zhang L, Kang W, Lei Y, Han Q, Zhang G, Lv Y, Li Z, Lou S and Liu Z: Granulocyte colony-stimulating factor treatment ameliorates liver injury and improves survival in rats with D-galactosamine-induced acute liver failure. Toxicol Lett 204: 92-99, 2011.

2. Gunning K: Hepatic failure. Anaesthesia \& Intensive Care Medicine 10: 124-126, 2009.

3. Lee WM: Acute liver failure. Semin Respir Crit Care Med 33: 36-45, 2012.

4. Matsumoto K, Mizumoto H, Nakazawa K, Ijima H, Funatsu K and Kajiwara T: Hepatic differentiation of mouse embryonic stem cells in a three-dimensional culture system using polyurethane foam. J Biosci Bioeng 105: 350-354, 2008.

5. Nakama T, Hirono S, Moriuchi A, Hasuike S, Nagata K, Hori T, Ido A, Hayashi K and Tsubouchi H: Etoposide prevents apoptosis in mouse liver with D-galactosamine/lipopolysaccharide-induced fulminant hepatic failure resulting in reduction of lethality. Hepatology 33: 1441-1450, 2001.

6. Chen L, Ren F, Zhang H, Wen T, Piao Z, Zhou L, Zheng S, Zhang J, Chen Y, Han Y, et al: Inhibition of glycogen synthase kinase $3 \beta$ ameliorates D-GalN/LPS-induced liver injury by reducing endoplasmic reticulum stress-triggered apoptosis. PLoS One 7: e45202, 2012.

7. Wang Y, Gao LN, Cui YL and Jiang HL: Protective effect of Danhong injection on acute hepatic failure induced by lipopolysaccharide and D-galactosamine in mice. Evid Based Complement Alternat Med 2014: 153902, 2014.

8. Wilhelm EA, Jesse CR, Roman SS, Nogueira CW and Savegnago L: Hepatoprotective effect of 3-alkynyl selenophene on acute liver injury induced by D-galactosamine and lipopolysaccharide. Exp Mol Pathol 87: 20-26, 2009.

9. Jeong YI, Jung ID, Lee CM, Chang JH, Chun SH, Noh KT, Jeong SK, Shin YK, Lee WS, Kang MS, et al: The novel role of platelet-activating factor in protecting mice against lipopolysaccharide-induced endotoxic shock. PLoS One 4: e6503, 2009.

10. Jin Q, Jiang S, Wu YL, Bai T, Yang Y, Jin X, Lian LH and Nan JX: Hepatoprotective effect of cryptotanshinone from Salvia miltiorrhiza in D-galactosamine/lipopolysaccharide-induced fulminant hepatic failure. Phytomedicine 21: 141-147, 2014.

11. Wei L, Ren F, Zhang X, Wen T, Shi H, Zheng S, Zhang J, Chen Y, Han Y and Duan Z: Oxidative stress promotes D-GalN/LPS-induced acute hepatotoxicity by increasing glycogen synthase kinase $3 \beta$ activity. Inflamm Res 63: 485-494, 2014.

12. Huang CC, Lin KJ, Cheng YW, Hsu CA, Yang SS and Shyur LF: Hepatoprotective effect and mechanistic insights of deoxyelephantopin, a phyto-sesquiterpene lactone, against fulminant hepatitis. J Nutr Biochem 24: 516-530, 2013.

13. Wen T, Wu ZM, Liu Y, Tan YF, Ren F and Wu H: Upregulation of heme oxygenase-1 with hemin prevents D-galactosamine and lipopolysaccharide-induced acute hepatic injury in rats. Toxicology 237: 184-193, 2007.

14. Liong EC, Xiao J, Lau TY, Nanji AA and Tipoe GL: Cyclooxygenase inhibitors protect D-galactosamine/lipopolysaccharide induced acute hepatic injury in experimental mice model. Food Chem Toxicol 50: 861-866, 2012.

15. Jaeschke H: Reactive oxygen and mechanisms of inflammatory liver injury. J Gastroenterol Hepatol 15: 718-724, 2000.
16. Jaeschke H: Reactive oxygen and mechanisms of inflammatory liver injury: Present concepts. J Gastroenterol Hepatol 26 (Suppl 1): 173-179, 2011.

17. Lian LH,Wu YL, Wan Y,LiX,Xie WX and Nan JX: Anti-apoptotic activity of gentiopicroside in D-galactosamine/lipopolysaccharide-induced murine fulminant hepatic failure. Chem Biol Interact 188: 127-133, 2010.

18. Wullaert A, Heyninck K and Beyaert R: Mechanisms of crosstalk between TNF-induced NF-kappaB and JNK activation in hepatocytes. Biochem Pharmacol 72: 1090-1101, 2006.

19. Lee HJ, Kim HC, Vitek L and Nam CM: Algae consumption and risk of type 2 diabetes: Korean National Health And Nutrition Examination Survey in 2005. J Nutr Sci Vitaminol (Tokyo) 56: $13-18,2010$

20. Choi YH, Kim EY, Mikami K and Nam TJ: Chemoprotective effects of a recombinant protein from Pyropia yezoensis and synthetic peptide against acetaminophen-induced Chang liver cell death. Int J Mol Med 36: 369-376, 2015.

21. Zhang LX, Cai CE, Guo TT, Gu JW, Xu HL, Zhou Y, Wang Y, Liu CC and He PM: Anti-cancer effects of polysaccharide and phycocyanin from Porphyra yezoensis. J Mar Sci Technol 19: 377-382, 2011.

22. Shin ES, Hwang HJ, Kim IH and Nam TJ: A glycoprotein from Porphyra yezoensis produces anti-inflammatory effects in liposaccharide-stimulated macrophages via the TLR4 signaling pathway. Int J Mol Med 28: 809-815, 2011.

23. Maiti R, Jana D, Das UK and Ghosh D: Antidiabetic effect of aqueous extract of seed of Tamarindus indica in streptozotocin-induced diabetic rats. J Ethnopharmacol 92: 85-91, 2004.

24. Gilani AH, Yaeesh S, Jamal Q and Ghayur MN: Hepatoprotective activity of aqueous-methanol extract of Artemisia vulgaris. Phytother Res 19: 170-172, 2005.

25. Liu LL, Gong LK, Wang H, Xiao Y, Wu XF, Zhang YH, Xue X, Qi XM and Ren J: Baicalin inhibits macrophage activation by lipopolysaccharide and protects mice from endotoxin shock. Biochem Pharmacol 75: 914-922, 2008.

26. Vimal V and Devaki T: Hepatoprotective effect of allicin on tissue defense system in galactosamine/endotoxin challenged rats. J Ethnopharmacol 90: 151-154, 2004.

27. Wang H, Xu DX, Lv JW, Ning $\mathrm{H}$ and Wei W: Melatonin attenuates lipopolysaccharide (LPS)-induced apoptotic liver damage in d-galactosamine-sensitized mice. Toxicology 237: 49-57, 2007.

28. Bindhumol V, Chitra KC and Mathur PP: Bisphenol A induces reactive oxygen species generation in the liver of male rats. Toxicology 188: 117-124, 2003.

29. Lekić N, Cerný D, Hořínek A, Provazník Z, Martínek J and Farghali H: Differential oxidative stress responses to D-galactosamine/lipopolysaccharide hepatotoxicity based on real time PCR analysis of selected oxidant/antioxidant and apoptotic gene expressions in rat. Physiol Res 60: 549-558, 2011.

30. Nordberg J and Arnér ES: Reactive oxygen species, antioxidants and the mammalian thioredoxin system. Free Radic Biol Med 31: 1287-1312, 2001.

31. Pearson G, Robinson F, Beers Gibson T, Xu BE, Karandikar M, Berman K and Cobb MH: Mitogen-activated protein (MAP) kinase pathways: Regulation and physiological functions. Endocr Rev 22: 153-183,2001.

32. Aggarwal BB: Nuclear factor-kappaB: The enemy within. Cancer cell 6: 203-208, 2004.

33. Tak PP and Firestein GS: NF-kappaB: A key role in inflammatory diseases. J Clin Invest 107: 7-11, 2001.

34. Ishizaki M, Kaibori M, Uchida Y, Hijikawa T, Tanaka H, Ozaki T, Tokuhara K, Matsui K, Kwon AH, Kamiyama Y, et al: Protective effect of FR183998, a Na$/ \mathrm{H}^{+}$exchanger inhibitor, and its inhibition of iNOS induction in hepatic ischemia-reperfusion injury in rats. Shock 30: 311-317, 2008.

35. Xia X, Su C, Fu J, Zhang P, Jiang X, Xu D, Hu L, Song E and Song Y: Role of $\alpha$-lipoic acid in LPS/d-GalN induced fulminant hepatic failure in mice: Studies on oxidative stress, inflammation and apoptosis. Int Immunopharmacol 22: 293-302, 2014.

36. Li R, Yuan C, Dong C, Shunang S and Choi MM: In vivo antioxidative effect of isoquercitrin on cadmium-induced oxidative damage to mouse liver and kidney. Naunyn Schmiedebergs Arch Pharmacol 383: 437-445, 2011.

37. Serhan CN and Oliw E: Unorthodox routes to prostanoid formation: New twists in cyclooxygenase-initiated pathways. J Clin Invest 107: 1481-1489, 2001. 